\title{
Lateral Surface of the Tongue
}

National Cancer Institute

\section{Source}

National Cancer Institute. Lateral Surface of the Tongue. NCI Thesaurus. Code C160983.

The side of the tongue. 